\title{
Acrylated Eudragitß E PO as a novel polymeric excipient with enhanced mucoadhesive properties for application in nasal drug delivery
}

Article

Accepted Version

Creative Commons: Attribution-Noncommercial-No Derivative Works 4.0

Porfiryeva, N. N., Nasibullin, S. F., Abdullina, S. G., Tukhbatullina, I. K., Moustafine, R. I. and Khutoryanskiy, V. V. (2019) Acrylated Eudragit@ E PO as a novel polymeric excipient with enhanced mucoadhesive properties for application in nasal drug delivery. International Journal of Pharmaceutics, 562. pp. 241-248. ISSN 0378-5173 doi: https://doi.org/10.1016/j.ijpharm.2019.03.027 Available at https://centaur.reading.ac.uk/83010/

It is advisable to refer to the publisher's version if you intend to cite from the work. See Guidance on citing.

To link to this article DOI: http://dx.doi.org/10.1016/j.ijpharm.2019.03.027

Publisher: Elsevier

All outputs in CentAUR are protected by Intellectual Property Rights law, including copyright law. Copyright and IPR is retained by the creators or other copyright holders. Terms and conditions for use of this material are defined in the End User Agreement. 


\section{www.reading.ac.uk/centaur}

\section{CentAUR}

Central Archive at the University of Reading

Reading's research outputs online 


\section{Acrylated Eudragit ${ }^{\circledR}$ E PO as a novel polymeric excipient with enhanced}

mucoadhesive properties for application in nasal drug delivery

3

Natalia N. Porfiryeva ${ }^{a}$, Shamil F. Nasibullin ${ }^{a}$, Svetlana G. Abdullina ${ }^{a}$, Irina K. Tukhbatullina ${ }^{a}$, Rouslan I. Moustafine ${ }^{a *}$ and Vitaliy V. Khutoryanskiy ${ }^{a, b^{*}}$.

anstitute of Pharmacy, Kazan State Medical University, 16 Fatykh Amirkhan Street, 420126

Kazan, Russian Federation

${ }^{b}$ Reading School of Pharmacy, University of Reading, Whiteknights, PO box 224, Reading RG66AD, United Kingdom

\section{Abstract}

Eudragit ${ }^{\circledR}$ E PO (EPO) is a terpolymer based on $N, N$-dimethylaminoethyl methacrylate with methylmethacrylate and butylmethacrylate, produced by Evonik Industries AG as a pharmaceutical excipient. In this work, EPO was chemically modified through reaction with acryloyl chloride. The successful modification of EPO was confirmed by FTIR, NMRspectroscopy, elemental and thermal analysis. The degree of acrylation was determined by permanganatometric titration. The slug mucosal irritation test was used to demonstrate nonirritant nature of EPO and its acrylated derivatives (AEPO). The mucoadhesive properties of EPO and AEPO were evaluated using freshly excised sheep nasal mucosa and it was demonstrated that acrylated polymers facilitated greater retention of sodium fluorescein on mucosal surfaces compared to solution mixture of this dye solution with EPO as well as free dye.

Keywords: Eudragit ${ }^{\circledR}$ E PO, mucoadhesion, acrylated polymers, slug mucosal irritation, nasal drug delivery, nose-to-brain delivery

*Correspondence: Dr Rouslan I. Moustafine rouslan.moustafine @ gmail.com and Prof Vitaliy V. Khutoryanskiy v.khutoryanskiy@ reading.ac.uk 


\section{Introduction}

Drug delivery through mucosal routes of administration offers numerous advantages such as improved bioavailability of active pharmaceutical ingredients, ease of therapy application and in some cases the possibility of targeting particular organs (Andrews et al, 2009; Khutoryanskiy, 2011; Khutoryanskiy, 2014). In recent years, nasal administration has gained a lot of interest due to the possibility for bypassing the blood-brain barrier and targeting the brain directly through drug absorption via olfactory mucosa (Gänger et al, 2018; Pires et al, 2018; Battaglia et al, 2018; Sonvico et al, 2018). This minimally invasive route to deliver drugs directly to the brain could potentially offer new opportunities for treating various neurodegenerative disorders such as Alzheimer's, Parkinson's and Huntington's diseases (Poovaiah et al, 2018).

Nasal cavity is an organ of human respiration, evolved to serve several functions, including air conditioning and protection from various pathogenic microorganisms. The protective function of the nasal cavity is achieved through mucociliary clearance, a physiological mechanism that helps to trap dust and microorganisms present in the air within the mucus blanket that is continuously produced and eventually moved into the digestive system. This dynamic and sticky nature of the mucus layer ensures the prevention of potential entry of microorganisms to the lungs (Washington et al, 2000; Hillery et al, 2001).

The mucus layer in the nasal cavity could act as a barrier that hampers the diffusion of drugs to reach epithelial cells, which may reduce the efficiency of therapeutic agents administered via intranasal route. One potential approach to improve the efficiency of drugs administered via intranasal route is the use of mucoadhesive dosage forms, capable to ensure longer residence in the nasal cavity (Ugwoke et al, 2005).

Cationic polymers are known to have excellent mucoadhesive properties due to their ability to interact with negatively charged mucins via electrostatic attraction forces. Examples of cationic polymers with proven mucoadhesive properties include chitosan (Sogias et al, 2008) and some synthetic polymers of methacrylate nature with tertiary-amino- and quaternary ammonium- functional groups (Keely et al, 2005; Fefelova et al, 2007). Some attempts were reported to improve mucoadhesive properties of chitosan and other polymers through their chemical functionalisation, for example, attachment of thiol- (Bernkop-Schnurch, 2004; Bernkop-Schnurch, 2005), acrylate- (Davidovich-Pinhas et al, 2011; Shitrit et al, 2017), methacrylate- (Kolawole et al, 2018), catechol- (Kim et al, 2015), maleimide- (Tonglairoum et al, 2016; Shtenberg et al, 2017; Sahatsapan et al, 2018) and other groups (Ways et al, 2018). 
Recently, we have reported the synthesis of mucoadhesive nanogels by polymerisation of 2-dimethylamino)ethyl methacrylate in the presence of $N, N$ '-methylene-bis-acrylamide as a crosslinking agent (Brannigan et al, 2017). The resulting nanogels were subsequently modified by the reaction with acryloyl chloride to introduce acrylated groups capable of forming covalent linkages with thiols present in mucins under physiological conditions. These acrylated nanogels exhibited superior mucoadhesive properties compared to the original poly((2dimethylamino)ethyl methacrylate) nanogels, when tested using bovine ocular mucosa.

Eudragit $^{\circledR}$ E PO (EPO) is a linear cationic polymer manufactured and marketed by Evonik Industries AG as a pharmaceutical excipient. EPO is a terpolymer that is composed of $\mathrm{N}, \mathrm{N}$-dimethylaminoethyl methacrylate (DMAEMA), methylmethacrylate and butylmethacrylate. The combination of these repeating units within this polymer ensures its solubility in water only under acidic conditions (insoluble in the mouth), which is applicable in the design of dosage forms with taste and odour masking. Once EPO coated dosage form moves into the stomach the acidity of the gastric juice will ensure its quick dissolution and drug release (Evonik technical notes, 2018). The ability of cationic EPO to form interpolyelectrolyte complexes with various anionic polymers was also previously used in the design of solid dosage forms for gastrointestinal delivery (Mustafin, 2011; Mustafin et al, 2011). Since EPO is an approved pharmaceutical excipient and it does contain DMAEMA units in the terpolymer structure, it opens up an interesting opportunity for its simple chemical modification using the chemistry previously described by Brannigan and Khutoryanskiy (2017) with the aim to prepare materials with enhanced mucoadhesive properties.

In the present study, we have modified EPO chemically through its reaction with acryloyl chloride, which resulted in formation of acrylated polymers. The resulting products were characterised using ${ }^{1} \mathrm{H}$ NMR and FTIR spectroscopy, thermal analysis, permanganatometric titration and elemental analysis. The biocompatibility of parent EPO and its acrylated derivatives were studied using slug mucosal irritation test. Liquid formulations were prepared using EPO and its acrylated derivatives with sodium fluorescein as a model compound and their retention on freshly excised sheep nasal mucosa was evaluated using fluorescent microscopy.

\section{Experimental part}

\subsection{Materials}

Eudragit ${ }^{\circledR}$ E PO (EPO) with weight-average molecular weight 135,000 was received as a gift from Evonik Röhm GmbH (Darmstadt, Germany). Acryloyl chloride was purchased from Alfa 
Aesar (Lancashire, United Kingdom). Tetrahydrofuran anhydrous, deuterated chloroform $\left(\mathrm{CDCl}_{3}\right)$, calcium chloride dehydrate, sodium chloride, potassium chloride, sodium fluorescein were obtained from Sigma-Aldrich (Gillingham, United Kingdom). Sulfuric acid, potassium permanganate and oxalic acid were received as a chemical standard from Uralhiminvest (UFA, Russia). Dialysis membranes (Mw cut-off $=12-14 \mathrm{kDa}$ ) were purchased from Medicell International Ltd (London, United Kingdom). Ultrapure water (Millipore, Bedford, MA, U.S.A) was used for all aqueous solutions and all other chemicals were used as supplied without modification.

\subsection{Methods}

\subsubsection{Synthesis of acrylated EPO}

Acrylated EPO was synthesized in a clean dry round-bottom flask with magnetic stirring. Briefly, $2 \mathrm{~g}$ of EPO was dissolved in $100 \mathrm{~mL}$ tetrahydrofuran with permanent stirring at room temperature. Acryloyl chloride was added dropwise to the resulting solutions with vigorous stirring during $20 \mathrm{~min}$ at room temperature. In order to achieve $50 \%$ and $25 \%$ of acryloylation $2.88 \mathrm{~mL}$ and $1.44 \mathrm{~mL}$ of acryloyl chloride were used and the resulting samples are referred as AEPO50 and AEPO25, respectively. The reaction mixtures were left for 72 hours at room temperature with gentle stirring. The reaction mixtures were then transferred to a dialysis membrane and dialyzed against deionised $\mathrm{H}_{2} \mathrm{O}$ (5L deionised $\mathrm{H}_{2} \mathrm{O}$ for 3 days changing the dialysis media three times a day). The resulting products were freeze-dried using Heto Power Dry LL 3000 freeze-drier (Thermo Electron Corporation).

\subsubsection{Preparation of artificial nasal fluid}

Artificial nasal fluid (ANF) was prepared according to the protocol described by Barbi et al. (2014) with minor changes. Solution was prepared by dissolving $7.45 \mathrm{~g} \mathrm{NaCl}, 1.29 \mathrm{~g} \mathrm{KCl}$ and $0.32 \mathrm{~g} \mathrm{CaCl}_{2} \cdot 2 \mathrm{H}_{2} \mathrm{O}$ in $1000 \mathrm{~mL}$ deionised water. The solution was left stirring overnight at room temperature. The artificial nasal fluid was kept at $37{ }^{\circ} \mathrm{C}$ in a water bath throughout the experiments.

\subsubsection{Fourier transform infrared spectroscopy (ATR-FTIR)}

The ATR-FTIR spectra of EPO, AEPO25 and AEPO50 powders were recorded using a Nicolet iS5 FTIR spectrometer (Thermo Scientific, U.S.A.) equipped with a DTGS detector. The samples were directly mounted over the iD5 smart single bounce ZnSe ATR crystal and 
scanned from 4000 to $400 \mathrm{~cm}^{-1}$. OMNIC spectra software was used for the analysis of results. Origin ${ }^{\circledR}$ software (Scientific Graphing \& Analysis software, Version 7.5, OriginLab Corp., USA) was used for plotting graphs.

\subsection{4. ${ }^{1} \mathrm{H}$ nuclear magnetic resonance spectroscopy $\left({ }^{1} \mathrm{H} \mathrm{NMR}\right)$}

${ }^{1} \mathrm{H}$ nuclear magnetic resonance spectra were recorded for EPO, AEPO25 and AEPO50 using a DPX $400 \mathrm{MHz}$ NMR spectrometer (Bruker, Germany). All samples were dissolved in deuterated chloroform and transferred to $5 \mathrm{~mm}$ Norell tubes (Standard Series ${ }^{\mathrm{TM}} 400 \mathrm{MHz}$ NMR). All chemical shifts were reported as $\delta$ in parts per million (ppm).

\subsubsection{Elemental analysis}

Elemental analysis was performed using Thermo Flash 2000 CHNS/O elemental analyzer (Thermo Fisher Scientific, Paisley, UK). The vacuum dried samples (at $40{ }^{\circ} \mathrm{C}$ for 2 days) were weighed into a crucible on a micro balance (Mettler Toledo XP6 Excellence Plus XP Micro Balance, Switzerland). The crucibles with samples were packed and placed into the combustion reactor via autosampler. Temperature in the oven was $900{ }^{\circ} \mathrm{C}$, and a gas flow rate was 10 $\mathrm{mL} / \mathrm{min}$. Calibration of the instrument was performed with atropine standard (Thermo Fisher Scientific, Paisley, UK). Eager Xperience Data Handling Software was used to analyze the results.

\subsubsection{Thermal analysis}

Modulated differential scanning calorimetry (mDSC) experiments were carried out using a Discovery DSCTM (TA Instruments, New Castle, DE, U.S.A.), equipped with a refrigerated cooling system (RCS90). These experiments were performed under dry nitrogen atmosphere at $50 \mathrm{~mL} / \mathrm{min}$ flow rate. Tzero ${ }^{\circledR}$ aluminum pans (TA Instruments, New Castle, DE, U.S.A.) were used in $\mathrm{mDSC}$ experiments. Indium and n-octadecane were used as standards to calibrate the DSC temperature scale. The modulation parameters used were: $2{ }^{\circ} \mathrm{C} / \mathrm{min}$ heating rate, $40 \mathrm{~s}$ period and $0.212^{\circ} \mathrm{C}$ amplitude.

Thermogravimetric analysis (TGA) was performed using Discovery TGA TM (TA Instruments, New Castle, DE, U.S.A.). Samples (10-15 mg) heated in aluminum pans from 25 to $500{ }^{\circ} \mathrm{C}$ at $10{ }^{\circ} \mathrm{C} / \mathrm{min}$. 
mDSC and TGA results were analysed using TRIOSTM software, version 3.1.5.3696 (TA Instruments, New Castle, DE, U.S.A.).

\subsubsection{Back permanganometric titration}

Briefly, $30 \mathrm{~mL}$ of $0.2 \mathrm{~N} \mathrm{H}_{2} \mathrm{SO}_{4}$ were placed in a conical flask with a Quickfit glass stopper. Approximately, 50-100 mg of acrylated polymer were then added to $\mathrm{H}_{2} \mathrm{SO}_{4}$ and left stirring until complete polymer dissolution. To this solution $10 \mathrm{~mL}$ of $0.1 \mathrm{~N}$ potassium permanganate was added, followed with $4 \mathrm{~mL}$ of $0.1 \mathrm{~N}$ oxalic acid added from a microburette. These solutions then were stirred and heated to $60^{\circ} \mathrm{C}$. This resulted in a change of solution colour from purple to brown. The presence of small quantities of oxalic acid resulted in reduction of some $\mathrm{MnO}_{4}{ }^{-}$ ions to $\mathrm{Mn}^{2+}$, which act as a catalyst and speed up the reaction of permanganate ions with oxalic acid added subsequently. The reaction mixtures were then slowly titrated with $0.1 \mathrm{~N}$ oxalic acid ( 4 drops per minute). Each titration was repeated in 5 times and the mean values were calculated.

The degree of EPO acrylation was determined according to the formula:

$$
X=\frac{\left(V_{1}-V_{2}\right) * K * T \times 100 \%}{a}
$$

where

$V_{1}$-volume of oxalic acid, consumed in the control experiment, $\mathrm{mL}$

$V_{2}$-volume of oxalic acid, consumed in the experiment, $\mathrm{mL}$

$K$-correction factor $(K=1.0000)$,

$T-$ a titre of oxalic acid to acrylated polymer $(T=1.2714 \mathrm{mg} / \mathrm{mL})$.

$a$-polymer sample weight, mg

\subsubsection{Slug mucosal irritation test}

Limax flavus slugs weighing 3-8 g were sourced locally in Harris Garden (Reading, UK). The slug mucosal irritation test was conducted using slightly modified procedure reported by Khutoryanskaya et al (2008). Solutions for slug mucosal irritation test were prepared by dissolving $20 \mathrm{mg}$ of EPO, AEPO25 and AEPO50 in $20 \mathrm{~mL}$ deionised water with pH adjusted to 5.7 with $1 \mathrm{M} \mathrm{NaOH}$ or $1 \mathrm{M} \mathrm{CH}_{3} \mathrm{COOH}$ solutions. Benzalkonium chloride (10 mg) was dissolved in $100 \mathrm{~mL}$ deionized water and adjusted to $\mathrm{pH}=5.7$ with $1 \mathrm{M} \mathrm{NaOH}$ to be used as a positive control. Each slug was kept in 0.5-1 L glass beakers with a tissue paper moistened with $20 \mathrm{~mL}$ ANF solution and left for two days at room temperature prior to experiments. Then 
each slug was washed with $2 \mathrm{~mL}$ of ANF solution, excess of moisture on their body was carefully removed with a tissue paper, and then they were put on Petri dishes with Whatman filter paper moistened with $2 \mathrm{~mL}$ sample solutions. The samples included positive control (1 $\%$ benzalkonium chloride), negative control (ANF), as well as $1 \mathrm{mg} / \mathrm{mL}$ solutions of EPO, AEPO25 and AEPO50. Slugs were kept in contact with the studied samples forl h, then they were taken out, washed with $10 \mathrm{~mL}$ of ANF and carefully wiped with a tissue paper. All slugs were then individually weighed before and after experiment using analytical balance. The mucus production (MP) was determined as a slug body weight loss and calculated according to the formula:

$$
\mathrm{MP}=\left(\mathrm{m}_{\mathrm{b}}-\mathrm{m}_{\mathrm{a}}\right) / \mathrm{m}_{\mathrm{b}} \times 100 \%,
$$

where $m_{a}$ and $m_{b}$ are the weights of a slug after and before each experiment, respectively.

All experiments were conducted using different slugs $(n=5)$.

\subsubsection{Retention studies}

Experiments on retention of polymer formulations on nasal mucosal surfaces were conducted using the fluorescent techniques developed and described by the Khutoryanskiy group earlier (Irmukhametova et al, 2011; Štorha et al, 2013; Mun et al, 2016; Kaldybekov et al, 2018; Ways et al, 2018). Sodium fluorescein solutions $(0.001 \mathrm{mg} / \mathrm{mL})$ were prepared in deionised water and used as a medium for dissolving polymer samples. Then, $10 \mathrm{mg}$ of EPO, AEPO25 or AEPO50 were dispersed in $10 \mathrm{~mL}$ of sodium fluorescein solutions and $\mathrm{pH}$ of these mixtures was adjusted to $\mathrm{pH}=5.7$. These dispersions were left for $24 \mathrm{~h}$ at room temperature with stirring until complete dissolution and were protected from light by aluminium foil.

Sheep mucosal tissues are commonly used in the ex vivo studies on nasal drug delivery (Gavini et al, 2008; Pund et al, 2013). Sheep heads were obtained from the local abattoir (Kazan, Russia) and transported to the laboratory in a cold box $\left(3-4{ }^{\circ} \mathrm{C}\right)$. The nasal septum tissue containing mucosal lining $(1.5 \times 3 \mathrm{~cm})$ was carefully dissected and extracted from each head with scissors; it was washed with $1 \mathrm{~mL}$ of ANF and placed on a microscopy slide. All tissues were used within $24 \mathrm{~h}$ after animal slaughter and each experiment was conducted in triplicate.

All experiments with retention of formulations on nasal mucosa were conducted at $37{ }^{\circ} \mathrm{C}$ in a thermostat. Images of mucosal surfaces were taken using fluorescent microscope (Olympus BX63), equipped with Alexa-488 filter. All images were of $4 \times$ magnification and were taken at 512 ms exposure time and 1376-1038 pixels. Initially, fluorescence images of mucosal 
tissues were recorded for each sample as a background fluorescence intensity. Then, $50 \mu \mathrm{L}$ solutions of $1 \mathrm{mg} / \mathrm{mL}$ EPO, AEPO25, AEPO50 containing $0.001 \mathrm{mg} / \mathrm{mL}$ sodium fluorescein were placed on mucosal surface and fluorescence images were recorded again. The mucosal tissues were then transferred to a thermostat and irrigated with ANF using a syringe pump (0.43 $\mathrm{mL} / \mathrm{min}$ ). Fluorescence images of these mucosal tissues were taken at different time points. ImageJ software was used for analysis of the resulting microscopy images by measuring the pixel intensity after each wash. Results were presented as fluorescence intensity values versus the volume of ANF. Background images were used to normalize the mean values by subtracting the background fluorescence after each wash. The experiments were conducted in triplicate. Solution of sodium fluorescein in deionised water $(0.001 \mathrm{mg} / \mathrm{mL})$ was used as a negative control.

\subsubsection{Statistical analysis}

GraphPad Prism statistical analysis software (version 5.0) was used to analyze data acquired during these experiments using one-way analysis of variance ANOVA and paired t-tests. Results were presented as the mean \pm standard deviation and probability of $p<0.05$ was considered as significant. All measurements were reported in triplicate, unless otherwise specified.

\section{Results and Discussion}

\section{Synthesis of acrylated EPO}

Previously, Brannigan and Khutoryanskiy (2017) have demonstrated that poly((2dimethylamino)ethyl methacrylate nanogels modified by reaction with acryloyl chloride exhibited greater retention on ocular mucosa compared to unmodified polymers. Similar modification is also possible for Eudragit ${ }^{\circledR} \mathrm{EPO}$, Eudragit ${ }^{\circledR} \mathrm{RL}$ and Eudragit ${ }^{\circledR} \mathrm{S} 100$ copolymers containing $25 \%, 10 \%$ and $5 \%$ of dimethylamino-groups, respectively (Mustafin, 2011; Moustafine et al, 2011; Moustafine et al, 2013). To demonstrate this possibility Eudragit ${ }^{\circledR}$ EPO was chosen for chemical modification using acryloylation according to the reaction scheme shown in Figure 1.Two batches of acrylated EPO with $25 \%$ and $50 \%$ substitution of the dimethylamino groups were synthesised (AEPO25 and AEPO50, respectively). (Figure 1 is here). 
254 The successful modification of EPO was confirmed by FTIR-spectroscopy (Figure 2). The 255 FTIR-spectra of EPO, AEPO25 and AEPO50 show the characteristic bands for non-ionised 256 dimethylamino groups between 2770-2824 $\mathrm{cm}^{-1}$ (Moustafine et al, 2011), whose intensity 257 becomes weaker with acryloylation. However, the spectra of AEPO25 and AEPO50 also show 258 the presence of a new band at $1605 \mathrm{~cm}^{-1}$ indicating the attachment of additional carbonyl 259 groups to EPO. Moreover, the FTIR spectra of AEPO25 and AEPO50 demonstrate the bands 260 at $960-966 \mathrm{~cm}^{-1}$ and $989 \mathrm{~cm}^{-1}$ corresponding to quaternary ammonium groups (Moustafine et al, 2012), which change depending on the degree of acryloylation.

Additionally, we also used ${ }^{1} \mathrm{H}-\mathrm{NMR}$ to confirm the chemical structure of modified polymers (Figure 3). The spectra of AEPO25 and AEPO50 show the appearance of a new multiplet between 5.98-6.44 ppm, which confirmed the presence of acryloyl groups. The intensity of these peaks decreases due to the reduction in the degree of substitution of dimethylamino groups. The appearance of a 5.98-6.44 ppm multiplet in the spectra of AEPO is generally consistent with NMR characterisation of acrylated PDMAEMA previously reported by Brannigan and Khutoryanskiy (2017), who used this method to determine the degree of acryloylation. However, unfortunately, the complex mixture of signals resulting from different repeating units of EPO leads to an overlap of many peaks; this made impossible to use ${ }^{1} \mathrm{H}$ NMR spectroscopy for quantitative determination of the degrees of acryloylation.

(Figure 3 is here)

Conjugation of acryloyl groups to EPO potentially should lead to some reduction in nitrogen content in the samples, which could be studied using elemental analysis. According to Table 1, nitrogen content in EPO is $4.30 \pm 0.12 \mathrm{wt} \%$. AEPO25 and AEPO50 showed $3.60 \pm 0.20 \mathrm{wt} \%$ and $3.79 \pm 0.24 \mathrm{wt} \%$ of nitrogen, respectively. This was a statistically significant reduction in nitrogen content compared to unmodified EPO $(p<0.05)$; however, there was no significant difference between AEPO25 and AEPO50 ( $p>0.05)$. The lack of statistically significant difference between AEPO25 and AEPO50 does not allow the calculation of the degree of acryloylation based on elemental analysis data. investigated. mDSC results demonstrate the presence of single glass transition events both in 
EPO and AEPO samples (Figure 4). The parent EPO displayed the presence of a $T g$ at 49.5 ${ }^{\circ} \mathrm{C}$, which is consistent with the previous reports (Moustafine et al, 2006; Menjoge and Kulkarni, 2007; Claeys et al, 2013). A reduction of dimethyl amino groups content and their partial replacement with quaternized nitrogen and acryloyl group resulted in copolymers with substantial increase in glass transition temperatures: $\mathrm{Tg}$ of EPO increased from $49.5^{\circ} \mathrm{C}$ to 94.5 ${ }^{\circ} \mathrm{C}$ and $81.9{ }^{\circ} \mathrm{C}$ for AEPO25 and AEPO50, respectively. The changes in $T g$ values of modified polymers compared to parent material qualitatively indicate the successful derivatization of EPO. Similar effects with increase in the $T g$ values upon reduction in the number of dimethyl amino groups content in a terpolymer structure were previously reported by Claeys et al (2013). A slightly unexpectedly lower $T g$ value of AEPO50 $\left(81.9^{\circ} \mathrm{C}\right)$ compared to AEPO25 $\left(94.5^{\circ} \mathrm{C}\right)$ could potentially be related to the effects of quaternization, similarly to quaternized polymers - Eudragit ${ }^{\circledR}$ RL and RS types, which are characterized by low Tgs (Eudragit ${ }^{\circledR}$ Application Guidelines, 2012).

(Figure 4 is here).

TGA thermogram of parent EPO (Figure 5) showed the first weight loss event at 271.6-316.8 ${ }^{\circ} \mathrm{C}(29.6 \%)$ possibly related to the removal of dimethylamino groups and formation of sixmembered cyclic anhydrides as proposed by Lin et al (1999). The second weight loss at 350.0$475.0{ }^{\circ} \mathrm{C}(68.9 \%)$ corresponds to a further complete decomposition of the terpolymer. The acrylated derivatives of EPO show distinctly different thermal decomposition profiles consisting of three degradation stages. In the case with AEPO, the first decomposition event begins at around $40{ }^{\circ} \mathrm{C}$ and finishes at $200{ }^{\circ} \mathrm{C}$ resulting in a weight loss of $3.9 \%$ and $4.0 \%$ for AEPO25 and AEPO50, respectively. This is likely related to the dehydration of a sample and removal of some moisture. It is interesting to note that moisture content in the parent EPO was practically not detectible, which may indicate that AEPO samples are more hydrophilic and hygroscopic compared to EPO. The second decomposition stage in AEPO25 is observed at 200.0-337.5 ${ }^{\circ} \mathrm{C}(31.9 \%)$, followed by the third weight loss at 337.5-475.0 ${ }^{\circ} \mathrm{C}(60.0 \%)$. AEPO50 displayed the second and third decomposition events at 200.0-337.5 ${ }^{\circ} \mathrm{C}(28.7 \%)$ and $337.5-475.0^{\circ} \mathrm{C}(62.6 \%)$, respectively. Overall, the second degradation event of acrylated EPO samples starts at $50-60{ }^{\circ} \mathrm{C}$ earlier compared to the first weight loss of parent EPO, but the final decomposition stages of the synthesized samples occurred in the similar range (at $400-450{ }^{\circ} \mathrm{C}$ ). A decrease in the thermal stability of modified EPO is possibly related to the presence of 
acryloyl groups, which are more chemically reactive and may undergo degradation at lower temperatures.

(Figure 5 is here)

\section{Determination of the degrees of acryloylation}

Since it was not possible to determine the degrees of acryloylation of EPO using ${ }^{1} \mathrm{H}$ NMR (due to the overlap of some characteristic signals in the spectrum) permanganatometric titration technique was used. This was a back-titration method, where an excess of potassium permanganate solution was used to oxidise unsaturated acryloyl groups in the polymer and unreacted permanganate was titrated with oxalic acid. Oxalate reacts very slowly with permanganate ions at room temperature, thus the solutions were titrated approximately at 60 ${ }^{\circ} \mathrm{C}$ to make this procedure more practical. In agreement with the manufacturer's specifications (Eudragit ${ }^{\circledR}$ Application Guidelines, 2013) EPO contains $22.6 \%$ of quaternary amino groups. According to this data, the modified polymers (AEPO25 and AEPO50) should have $5.65 \%$ and $11.30 \%$ of acryloyl groups, respectively, which was confirmed by permanganatometry (Table 1).

(Table 1 is here).

\section{Toxicological Investigation}

In order to evaluate toxicological properties of modified polymers slug mucosal irritation test was performed. This test was established and validated as a reliable method for preliminary evaluation of irritation potential of chemicals to various mucosal membranes, including studies of nasal irritation (Adriaens et al, 2001; Adriaens and Remon, 2002; Lenoir et al, 2011; Lenoir et al, 2013). In this test, the first sign of good biocompatibility is colorless mucus, secreted by slugs. Second, the amount of mucus production, which increased in stronger irritating conditions (Khutoryanskaya et al, 2008; Adriaens et al, 1999; Adriaens and Remon, 2002). In a positive control experiment ( $1 \%$ benzalkonium chloride) slugs suffered a severe irritation, with $28.02 \pm 2.70 \%$ production of yellow mucus (Figure 6), which is consistent with the previous reports (Khutoryanskaya et al, 2008). The slugs exposed to solutions with EPO produce $4.55 \pm 2.26 \%$ colorless mucus, confirming non-irritating nature of this polymer. The mucus production values recorded for AEPO25 and AEPO50 were 3.38 \pm 1.37 and in 4.40 \pm 2.29 $\%$, respectively. No significant difference was observed between mucus production values 
recorded for negative control, EPO, AEPO25 and AEPO50 ( $\mathrm{p}<0.05$ ), indicating non-irritating nature of modified EPO.

(Figure 6 is here).

\section{Mucoadhesion studies}

The retention studies with fluorescent detection of different mucoadhesive formulations on different surfaces were described in previous publications (Irmukhametova et al, 2011; Storha et al, 2013; Cook et al, 2015; Mun et al, 2016; Kaldybekov et al, 2018; Ways et al, 2018). This flow-through test evaluating the retention of formulations on mucosal surfaces usually gives good correlation with other methods (e.g. tensile studies) used to characterize mucoadhesive properties (Kolawole et al, 2019). In the present work the retention properties of EPO, AEPO25, AEPO50 solutions containing sodium fluorescein were studied on freshly excised sheep nasal mucosa, irrigated with artificial nasal fluid (ANF). Fluorescent images of these samples are presented in Figure 7.

(Figure 7 is here).

Figure 8 shows the retention of EPO, AEPO25, AEPO50 solutions containing sodium fluorescein on sheep nasal mucosa after analysis of the fluorescent images. It was established that parent EPO exhibits mucoadhesive properties and retains the dye on mucosal surface better compared to free sodium fluorescein. Approximately, $3.19 \pm 1.40 \%$ of fluorescence remained on nasal mucosa after 60 min washing. This good retention of the dye mediated with EPO on mucosal surfaces is likely to be related to its cationic nature that ensures electrostatic attraction of this polymer to negatively charged mucosal surface. AEPO25 and AEPO50 facilitated even greater retention of the dye on nasal mucosa compared to EPO: their retention after 60 mins of washing is $6.34 \pm 1.01$ and $10.89 \pm 3.48 \%$, respectively. This difference is statistically significant $(p<0.05)$, demonstrating superior mucoadhesive performance of acrylated polymers.

(Figure 8 is here)

\section{Conclusions}

This study demonstrated successful chemical modification of Eudragit ${ }^{\circledR} \mathrm{E}$ PO through reaction with acryloyl chloride resulting in acrylated polymers. The structure and physicochemical properties of these polymers were studied using FTIR and ${ }^{1} \mathrm{H}$ NMR spectroscopies, mDSC and 
TGA thermal methods as well as by back permanganatometric titration. The slug mucosal irritation test was used to demonstrate non-irritant nature of modified polymers. Acrylated polymers exhibited superior mucoadhesive properties on nasal mucosa tissue compared to parent Eudragit ${ }^{\circledR}$ E PO. Acrylated EPO can potentially be used as a mucoadhesive material for formulation of dosage forms for transmucosal drug delivery. To the best of our knowledge, this is the first study reporting the chemical modification of EPO with the aim to enhance its mucoadhesive properties.

\section{Acknowledgments}

The authors acknowledge the Ministry of Education and Science of the Republic of Tatarstan (Russia) for “Algarysh” grant supporting N.N.P. visit to University of Reading. The authors are grateful to Prof. Sergei V. Boichuk (Kazan State Medical University) for his technical help with mucoadhesion experiments. The authors are also grateful to Dr. Daulet B. Kaldybekov and Roman V. Moiseev (University of Reading) for their help with slug mucosal irritation assay. Chemical Analysis Facility (University of Reading) is also acknowledge for providing access to ${ }^{1} \mathrm{H}$ NMR experiments.

\section{References}

Adriaens E., Dierckens K., Bauters T.G., Nelis H.J., van Goethem F., Vanparys P., Remon J.P., 2001. The mucosal toxicity of different benzalkonium chloride analogues evaluated with an alternative test using slugs. Pharm. Res. 18, 937- 942.

Adriaens E., Remon J. P., 2002. Evaluation of an Alternative Mucosal Irritation Test Using Slugs. Toxicol. Appl. Pharmacol. 182, 169-175.

Andrews G., Laverty T.P., Jones D., 2009. Mucoadhesive Polymeric Platforms for Controlled Drug Delivery. Eur. J. Pharm. Biopharm. 71, 505-518.

Barbi Mda S., Carvalho F.C., Kiill C.P., Barud Hda S., Santagneli S.H., Ribeiro S.J. Gremião M.P., 2014. Preparation and Characterization of Chitosan Nanoparticles for Zidovudine Nasal Delivery. J. Nanosci. Nanotechnol. 14, 1-10.

Battaglia L., Panciani P.P., Muntoni E., Capucchio M.T., Biasibetti E., De Bonis P., Mioletti S., Fontanella M., Swaminathan S., 2018. Lipid nanoparticles for intranasal administration: application to nose-to-brain delivery. Exp. Opin. Drug Deliv. 15, 369-378. 
Bernkop-Schnürch A., 2005. Thiomers: A new generation of mucoadhesive polymers. Adv. Drug Deliv. Rev. 57, 1569-1582.

Bernkop-Schnürch A., Hornof M., Guggi D., 2004. Thiolated chitosans. Eur. J. Pharm. Biopharm. 57, 9-17.

Brannigan R.P., Khutoryanskiy V.V., 2017. Synthesis and evaluation of mucoadhesive acryloyl-acrylated PDMAEMA nanogels for ocular drug delivery. Colloids and Surfaces B: Biointerfaces. 155, 538-543.

Claeys B., De Coen R., Geest B.G., de la Rosa V.R., Hoogenboom R., Carleer R., Adriaensens P., Remon J.P., Vervaet C., 2013. Structural modifications of polymethacrylates: Impact on thermal behavior and release characteristics of glassy solid solutions. Eur. J. Pharm. Biopharm. 85, 1206-1214.

Cook M.T., Schmidt S.A., Lee E., Samprasit W., Opanasopit P., Khutoryanskiy V.V., 2015. Synthesis of mucoadhesive thiol-bearing microgels from 2-(acetylthio)ethylacrylate and 2-hydroxyethylmethacrylate: novel drug delivery systems for chemotherapeutic agents to the bladder. J. Mater. Chem. B 3, 6599-6604.

Davidovich-Pinhas M., Bianco-Peled H., 2011. Alginate-PEGAc: a new mucoadhesive polymer. Acta Biomater. 7, 625-633.

Dhondt M.M.M., Adriaens E., Van Roey J., Remon J.P., 2005. The evaluation of the local tolerance of vaginal formulations containing dapivirine using the Slug Mucosal Irritationtestand the rabbit vaginal irritationtest. Eur J. Pharm. Biopharm. 60, 419-425.

Dittgen M., Durrani M., Lehmann K., 1997. Acrylic polymers. A review of pharmaceutical applications. STP Pharm. Sci. 7, 403-437.

Evonik Pharma Polymers. Eudragit ${ }^{\circledR}$ Application Guidelines.12th Edition, Evonik Pharma Polymers, Darmstadt. 2013, 44-111.

Evonik technical notes, EUDRAGIT ${ }^{\circledR}$ EPO ReadyMix - Evonik Industries, https://healthcare.evonik.com/sites/lists/NC/DocumentsHC/EUDRAGIT-E-PO

ReadyMix-EN.pdf, accessed 07 Dec 2018 
Fefelova N.A., Nurkeeva Z.S., Mun G.A., Khutoryanskiy V.V., 2007. Mucoadhesive interactions of amphiphilic cationic copolymers based on [2-(methacryloyloxy) ethyl] trimethylammonium chloride. Int. J. Pharm., 339, 25-32.

Gavini E., Rassu G., Muzzarelli C., Cossu M., Giunchedi P., 2008. Spray-dried microspheres based on methylpyrrolidinone chitosan as new carrier for nasal administration of metoclopramide. Eur. J. Pharm. Biopharm., 68, 245-252.

Gänger S., Schindowski K., 2018. Tailoring Formulations for Intranasal Nose-to-Brain Delivery: A Review on Architecture, Physico-Chemical Characteristics and Mucociliary Clearance of the Nasal Olfactory Mucosa. Pharmaceutics. 10(3), 116.

Hillery A.M., Lloyd A.W., Swarbrick J., 2001. Drug Delivery and Targeting: For Pharmacists and Pharmaceutical Scientists. CRC Press, 496 p.

Irmukhametova G.S., Mun G.A., Khutoryanskiy V.V., 2011. Thiolated mucoadhesive and PEGylated nonmucoadhesive organosilica nanoparticles from 3mercaptopropyltrimethoxysilane. Langmuir 27, 9551-955.

Kaldybekov D.B., Tonglairoum P., Opanasopit P., Khutoryanskiy V.V., 2018. Mucoadhesive maleimide-functionalised liposomes for drug delivery to urinary bladder. Eur. J. Pharm. Sci. 111, 83-90.

Keely S., Rullay A., Wilson C., Carmichael A., Carrington S., Corfield A., Haddleton D.M., Brayden D.J., 2005. In vitro and ex vivo intestinal tissue models to measure mucoadhesion of poly (methacrylate) and N-trimethylated chitosan polymers. Pharm. Res. 22, 38-49.

Khutoryanskaya O.V., Mayeva Z.A., Mun G.A., Khutoryanskiy V.V., 2008. Designing Temperature-Responsive Biocompatible Copolymers and Hydrogels Based on 2Hydroxyethyl(meth)acrylates. Biomacromolecules 9, 3353-3361.

Khutoryanskiy V.V., 2011. Advances in Mucoadhesion and mucoadhesive polymers. Macromol.Biosci.11, 748-764.

Khutoryanskiy V.V., 2018. Beyond PEGylation: alternative surface-modification of nanoparticles with mucus-inert biomaterials. Adv. Drug Deliv. Rev. 124, 140-149. 
Khutoryanskiy V.V., 2014. Mucoadhesive materials and drug delivery systems. Wiley and Sons.

Kim K., Ji K.K., Ryu J.H., Lee H., 2015. Chitosan-catechol: A polymer with long-lasting mucoadhesive properties. Biomaterials, 52, 161-170.

Kolawole O.M., Lau W.M., Khutoryanskiy V.V., 2018. Methacrylated chitosan as a polymer with enhanced mucoadhesive properties for transmucosal drug delivery. Int. J. Pharm., 550, 123-129.

Kolawole O.M., Lau W.-M., Khutoryanskiy V.V., 2019. Chitosan / $\beta$-glycerophosphate in situ gelling mucoadhesive systems for intravesical delivery of mitomycin-C. Int. J. Pharm. X, 1, 100007.

Lenoir J., Adriaens E., Remon J.P., 2011. New aspects of the Slug Mucosal Irritation assay: predicting nasal stinging, itching and burning sensations. J. Appl. Toxicol., 31, 640648.

Lenoir J., Bachert C., Remon J.P., Adriaens E., 2013. The Slug Mucosal Irritation (SMI) assay: a tool for the evaluation of nasal discomfort. Toxicol in Vitro, 27, 1954-1961.

Lin S.Y., Yu H., Li M.J., 1999. Formation of six-membered cyclic anhydrides by thermally induced intramolecular ester condensation in Eudragit ${ }^{\circledR}$ E film. Polymer 40, 3589-3593.

Menjoge A.R., Kulkarni M.G., 2007. Mechanistic investigation of phase behavior in Eudragit ${ }^{\circledR}$ E blends. Int. J. Pharm. 343, 106-121.

Moustafine R.I., Zaharov I.M., Kemenova V.A., 2006. Physicochemical characterization and drug release properties of Eudragit ${ }^{\circledR}$ EPO/Eudragit ${ }^{\circledR}$ L100-55 interpolyelectrolyte complexes. Eur. J. Pharm. Biopharm. 63, 26-36.

Moustafine R.I., Bobyleva V.L., Bukhovets A.V., Garipova V.R., Kabanova T.V., Kemenova V.A., Van den Mooter G., 2011. Structural transformations during swelling of polycomplex matrices based on countercharged (meth)acrylate copolymers (Eudragit ${ }^{\circledR}$ EPO/Eudragit ${ }^{\circledR}$ L 100-55). J. Pharm. Sci. 100, 874-885.

Moustafine R.I., Bodrov A.V., Kemenova V.A., Rombaut P., Van den Mooter G., 2012. Drug release modification by interpolymer interaction between countercharged types of Eudragit ${ }^{\circledR}$ RL 30D and Eudragit ${ }^{\circledR}$ FS 30D in double-layer films. Int. J. Pharm. 439, 17-21 
Moustafine R.I., Bukhovets A.V., Sitenkov A.Y., Kemenova V.A., Rombaut P., Van den Mooter G., 2013. Eudragit ${ }^{\circledR}$ EPO as a complementary material for designing oral drug delivery systems with controlled release properties: comparative evaluation of new interpolyelectrolyte complexes with countercharged Eudragit ${ }^{\circledR}$ L100 copolymers. Mol. Pharm.10, 2630-2641.

Mun E.A., Williams A.C., Khutoryanskiy V.V., 2016. Adhesion of thiolated silica nanoparticles to urinary bladder mucosa: effects of PEGylation, thiol content and particle size. Int. J. Pharm. 512, 32-38.

Mustafin R.I. 2011. Interpolymer combinations of chemically complementary grades of Eudragit copolymers: A new direction in the design of peroral solid dosage forms of drug delivery systems with controlled release (review). Pharm. Chem. J. 45, 285-295.

Mustafin R.I., Kabanova T. V., Semina I. I., Bukhovets A. V., Garipova V. R., Shilovskaya E. V., Nasibullin Sh. F., Sitenkov A. Yu., Kazakova R. R., Kemenova V. A. 2011. Biopharmaceutical assessment of a polycomplex matrix system based on Carbomer 940 and Eudragit EPO for colon-specific drug delivery. Pharm. Chem. J. 45, 491-494.

Pires P.C., Santos A.O., 2018. Nanosystems in nose-to-brain drug delivery: A review of non-clinical brain targeting studies. J. Control. Release, 270, 89-100.

Poovaiah N., Davoudi Z., Peng H., Schlichtmann B., Mallapragada S., Narasimhan B., Wang Q., 2018. Treatment of neurodegenerative disorders through the blood-brain barrier using nanocarriers. Nanoscale, 10, 16962-16983.

Pund S., Rasve G., Borade G., 2013. Ex vivo permeation characteristics of venlafaxine through sheep nasal mucosa. Eur. J. Pharm. Sci., 48, 195-201.

Sahatsapan N., RojanarataT., Ngawhirunpat T., Opanasopit P., Tonglairoum P., 2018. 6Maleimidohexanoic acid-grafted chitosan: A new generation mucoadhesive polymer. Carb. Polym., 202, 258-264.

Shitrit Y., Bianco-Peled H., 2017. Acrylated chitosan for mucoadhesive drug delivery systems. Int. J. Pharm., 517, 247-255.

Sogias I.A., Williams A.C., Khutoryanskiy V.V., 2008. Why is chitosan mucoadhesive? Biomacromolecules, 9, 1837-1842. 
Sonvico F., Clementino A., Buttini F., Colombo G., Pescina S., Stanisçuaski Guterres S., Raffin Pohlmann A., Nicoli S., 2018. Surface-Modified Nanocarriers for Nose-to-Brain Delivery: From Bioadhesion to Targeting Pharmaceutics. Pharmaceutics, 10(1), 34.

Shtenberg Y., Goldfeder M., Schroeder A., Bianco-Peled H., 2017.Alginate modified with maleimide-terminated PEG as drug carriers with enhanced mucoadhesion. Carbohydrate Polym., 175, 337-346.

Štorha A., Mun E.A., Khutoryanskiy V.V., 2013. Synthesis of thiolated and acrylated nanoparticles using thiol-ene click chemistry: towards novel mucoadhesive materials for drug delivery. RSC Adv. 3, 12275-12279.

Tonglairoum P., Brannigan R.P., Opanasopit P., Khutoryanskiy V.V., 2016. Maleimidebearing nanogels as novel mucoadhesive materials for drug delivery, J. Mater. Chem. B 4 (40), 6581-6587.

Ugwoke M.I., Agu R.U., Verbeke N., Kinget R., 2005. Nasal mucoadhesive drug delivery: Background, applications, trends and future perspectives. Adv. Drug Deliv. Rev. 57, 16401665 .

Washington N., Washington C., Wilson C., 2000. Physiological Pharmaceutics: Barriers to Drug Absorption. CRC Press, 328 p.

Ways T.M., Lau W.M., Khutoryanskiy V.V., 2018. Chitosan and its derivatives for application in mucoadhesive drug delivery systems, Polymers 10 (3), 267.

Ways T.M.M., Lau W.M., Ng K. W., Khutoryanskiy V.V., 2018. Synthesis of thiolated, PEGylated and POZylated silica nanoparticles and evaluation of their retention on rat intestinal mucosa in vitro, Eur. J. Pharm. Sci. 122, 230-238. 
544 Tables:

545

546 Table 1. Quantitation and physicochemical properties of acrylated EPO

\begin{tabular}{ccccc}
\hline Sample & $\begin{array}{c}\text { Acryloyl } \\
\text { chloride } \\
(\mathrm{mL})\end{array}$ & $\begin{array}{c}\text { Content of } \\
\text { acryloyl } \\
\text { groups }^{\mathrm{a}}(\%)\end{array}$ & $\begin{array}{c}\text { Degree of } \\
\text { acryloylation } \\
(\%)^{\mathrm{b}}\end{array}$ & $\begin{array}{c}\text { Nitrogen content } \\
(\%)^{\mathrm{c}}\end{array}$ \\
EPO & 0 & 0 & 0 & $4.30 \pm 0.12$ \\
AEPO25 & 1.44 & $5.7 \pm 0.4$ & $25.1 \pm 1.6$ & $3.60 \pm 0.20$ \\
& & & & \\
AEPO50 & 2.88 & $11.3 \pm 0.2$ & $50.0 \pm 0.8$ & $3.79 \pm 0.24$
\end{tabular}
analysis. 


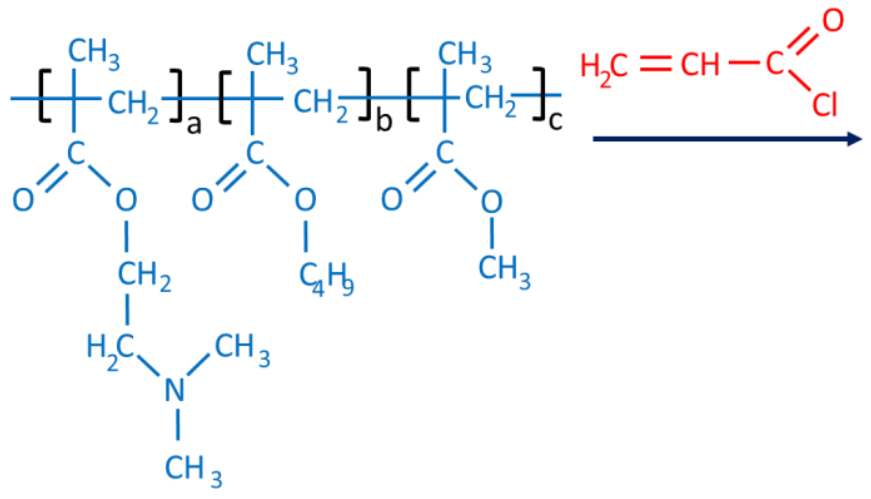

EPO

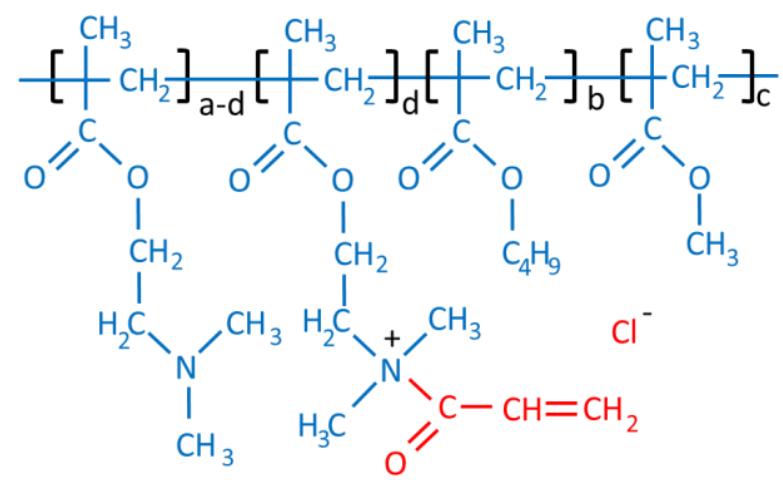

Acrylated EPO

551

552 Figure 1. Synthesis of acrylated EPO $\left(25^{\circ} \mathrm{C}, 72 \mathrm{~h}\right)$.

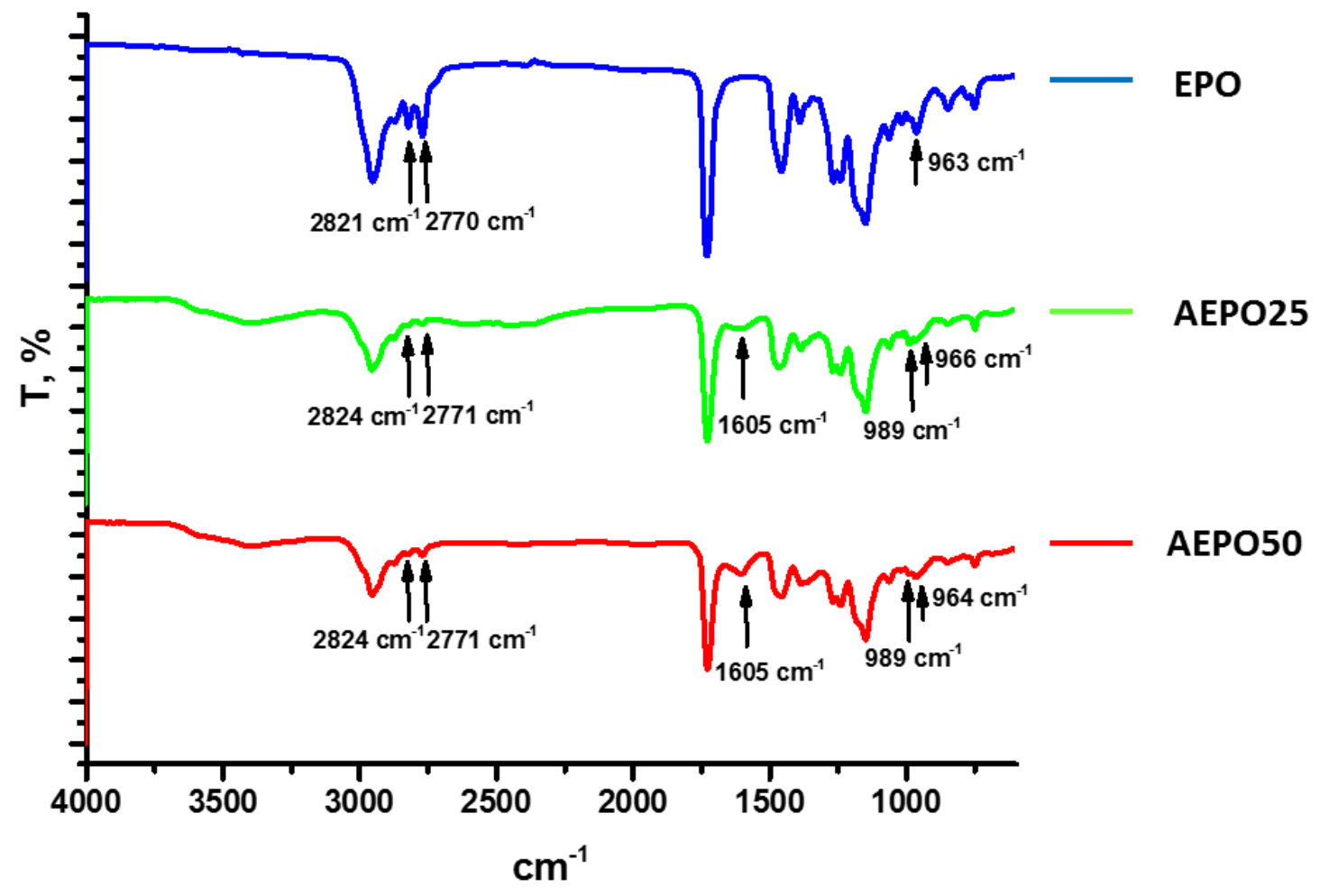

553 Figure 2. FTIR spectra of EPO, AEPO25 and AEPO50. 


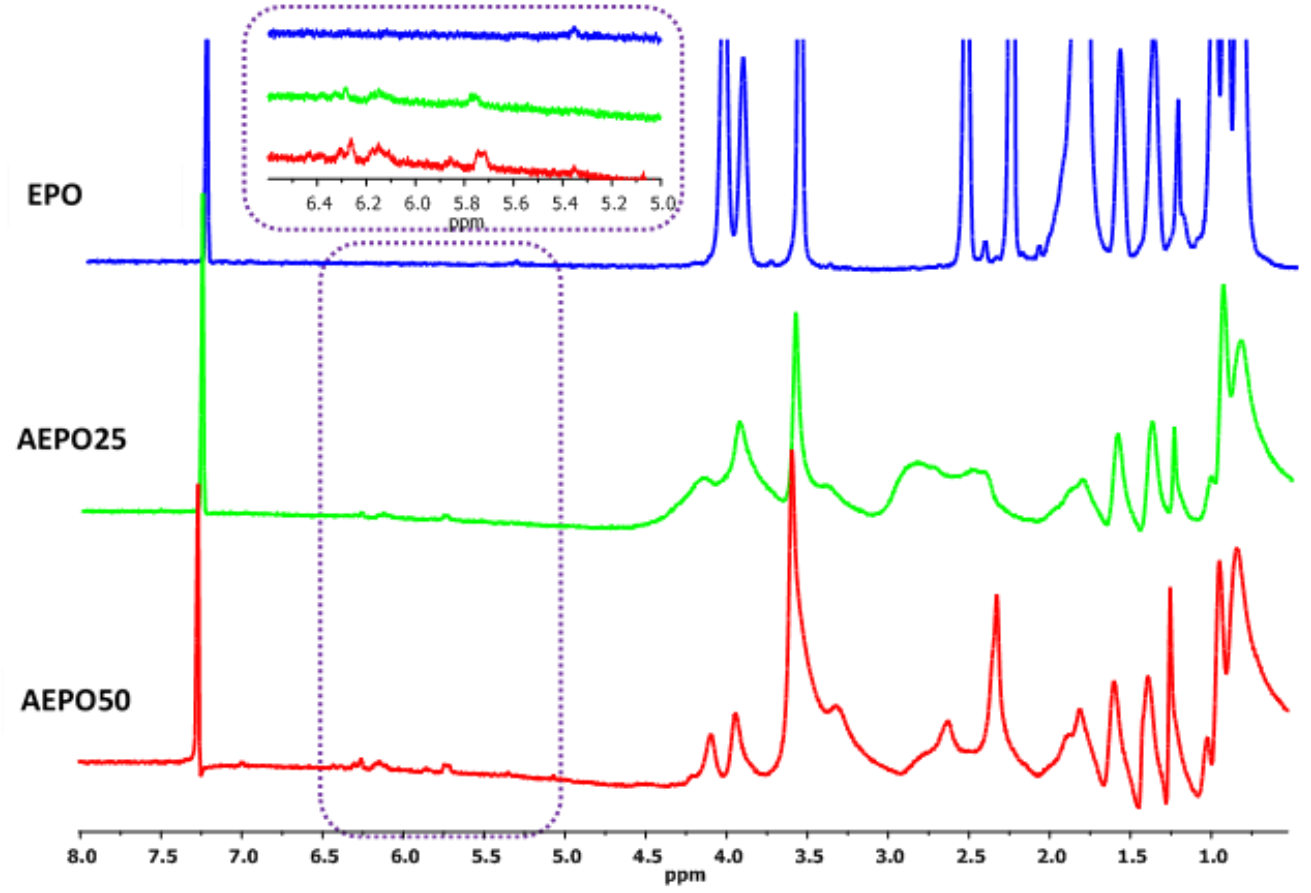

564

Figure 3. ${ }^{1} \mathrm{H}$ NMR spectra of EPO, AEPO25 and AEPO50 $\left(\mathrm{CDCl}_{3}, 400 \mathrm{MHz}\right)$.

565

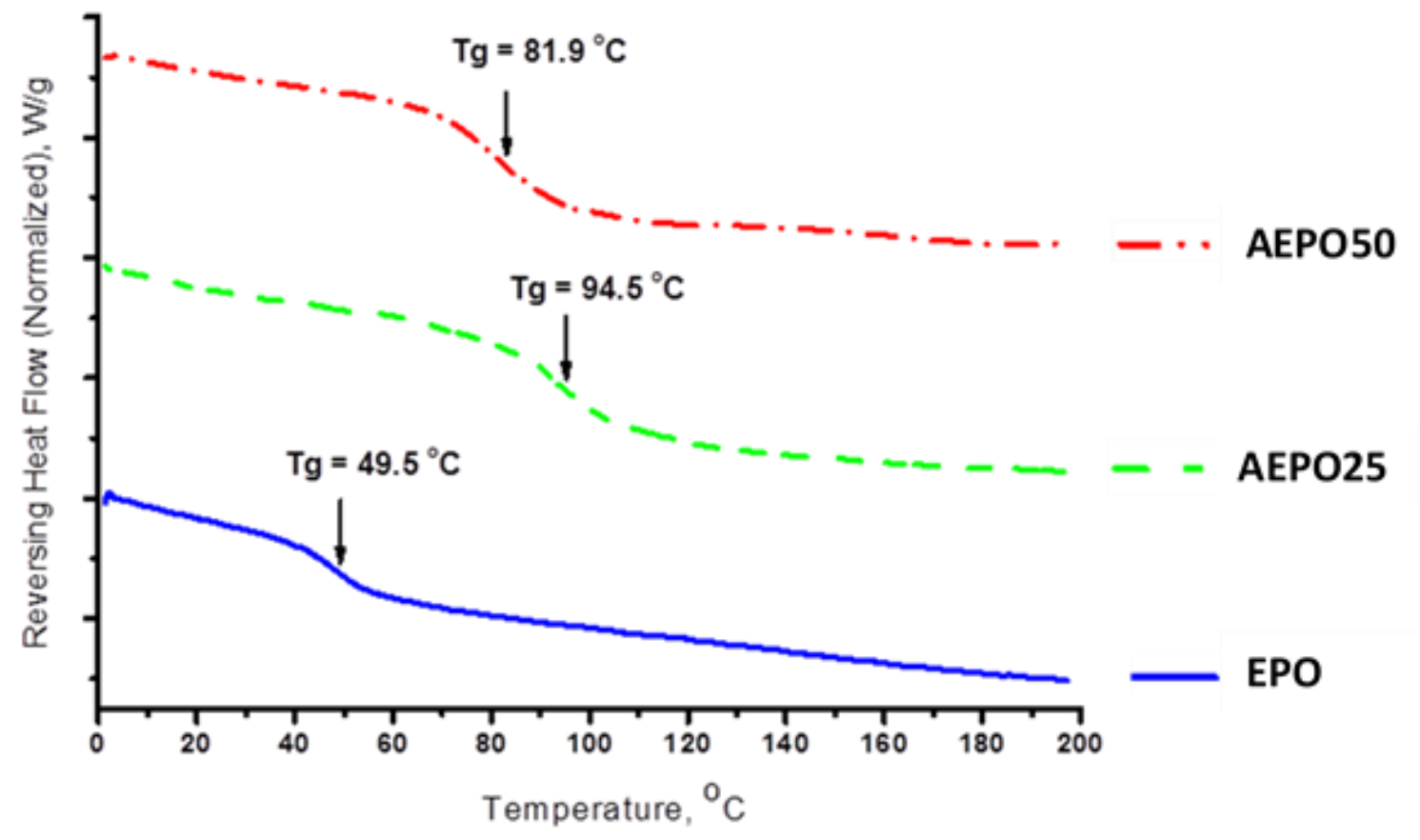

566

Figure 4. mDSC thermograms of EPO,AEPO25 and AEPO50. 


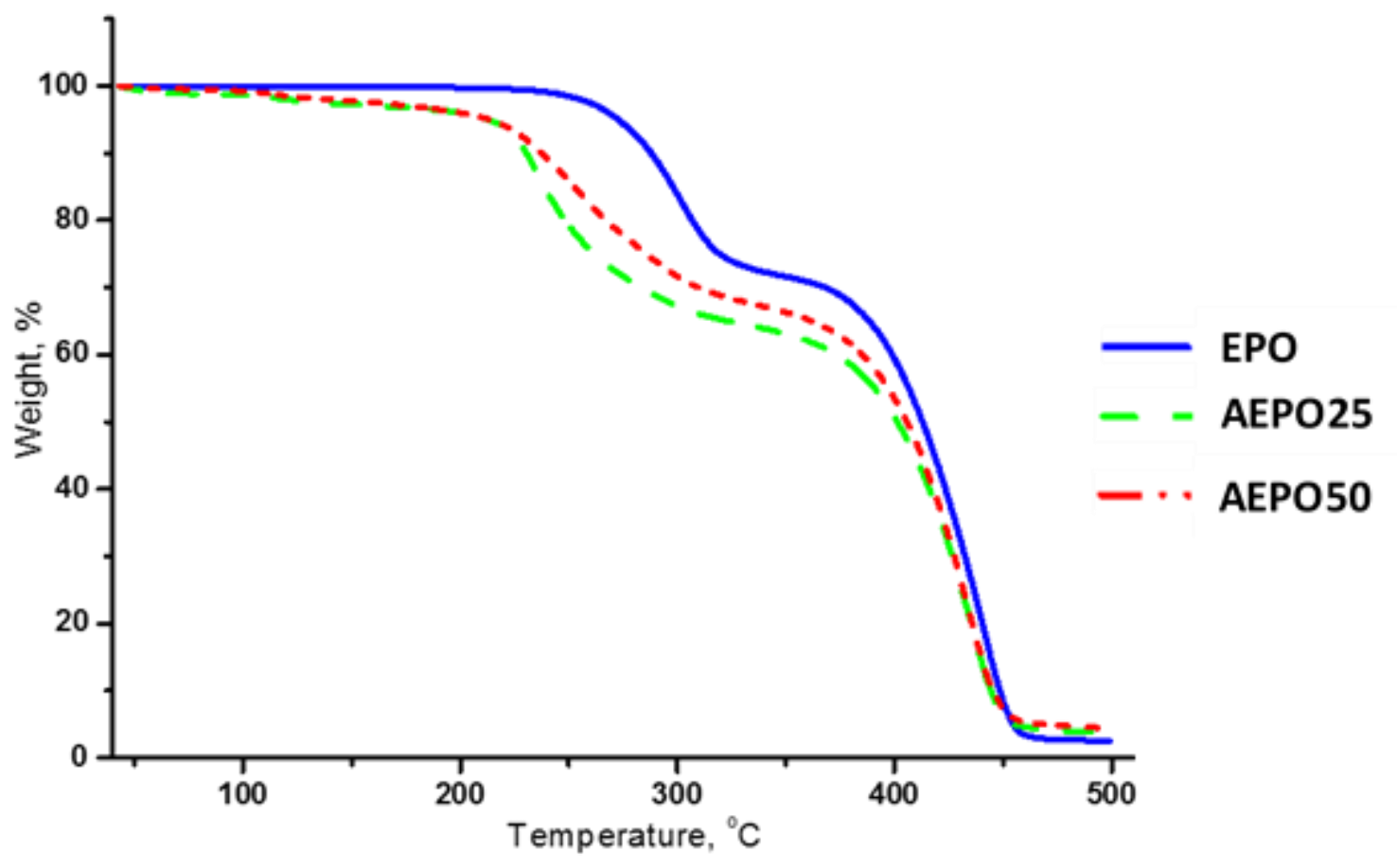

568

569 Figure 5. TGA thermograms of EPO, AEPO25 and AEPO50.

570

571 


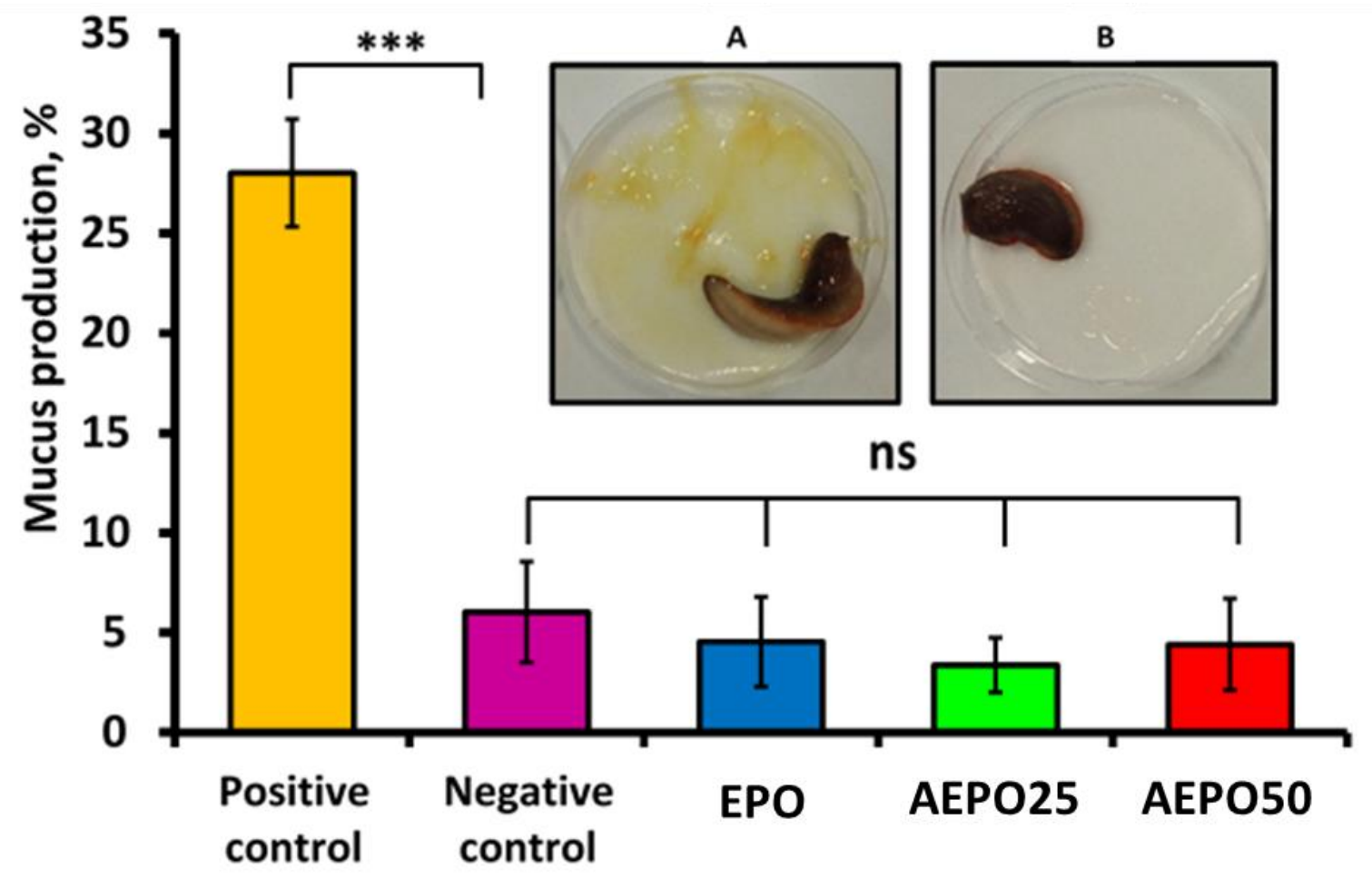

572

573 Figure 6. Mucus production by Limax flavus slugs in response to the contact with solutions of 5741 wt \% benzalkonium chloride (positive control), ANF (negative control), 0.1 wt \% EPO, 575 AEPO25 and AEPO50 (pH=5.7). Data are expressed as mean \pm standard deviation $(\mathrm{n}=5)$. Inset: 576 exemplar images of Limax flavus slugs in positive (A) and negative (B) controls experiment. 


\section{EPO-sodium fluorescein}
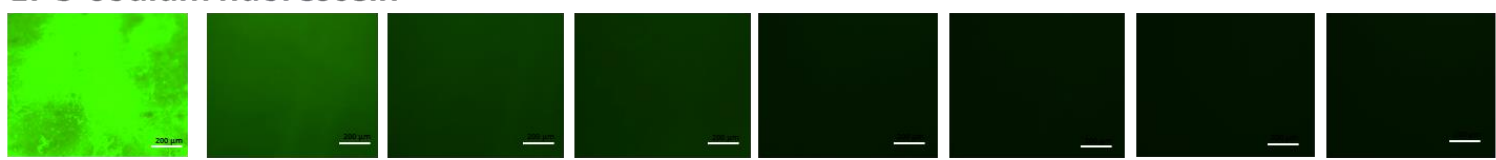

AEPO25-sodium fluorescein
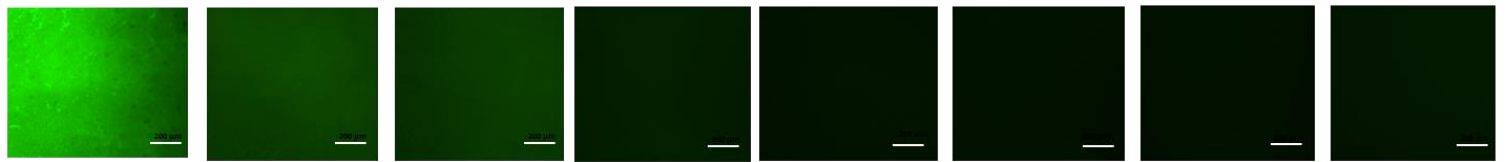

AEPO50-sodium fluorescein
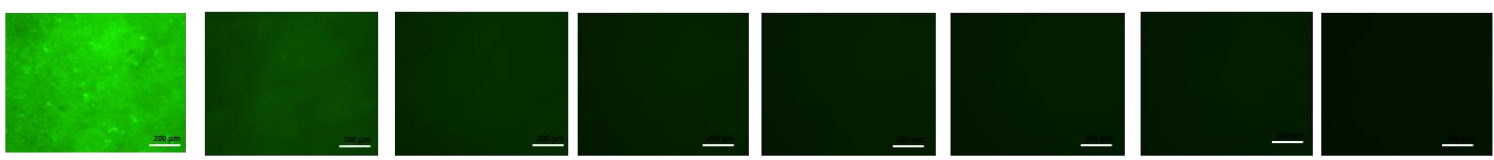

Sodium fluorescein
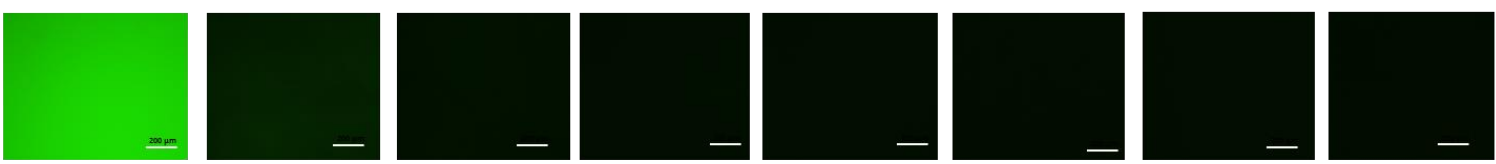

0

5

10

20

30

40

50

60

Time, $\min$

578 Figure 7. Fluorescent images showing retention of $1 \mathrm{mg} / \mathrm{mL}$ EPO, AEPO25, AEPO50

579 solutions with $0.001 \mathrm{mg} / \mathrm{mL}$ sodium fluorescein, and pure $0.001 \mathrm{mg} / \mathrm{mL}$ sodium fluorescein

580 solution on sheep nasal mucosa as washed with ANF. Scale bar is $200 \mu \mathrm{m}$. 


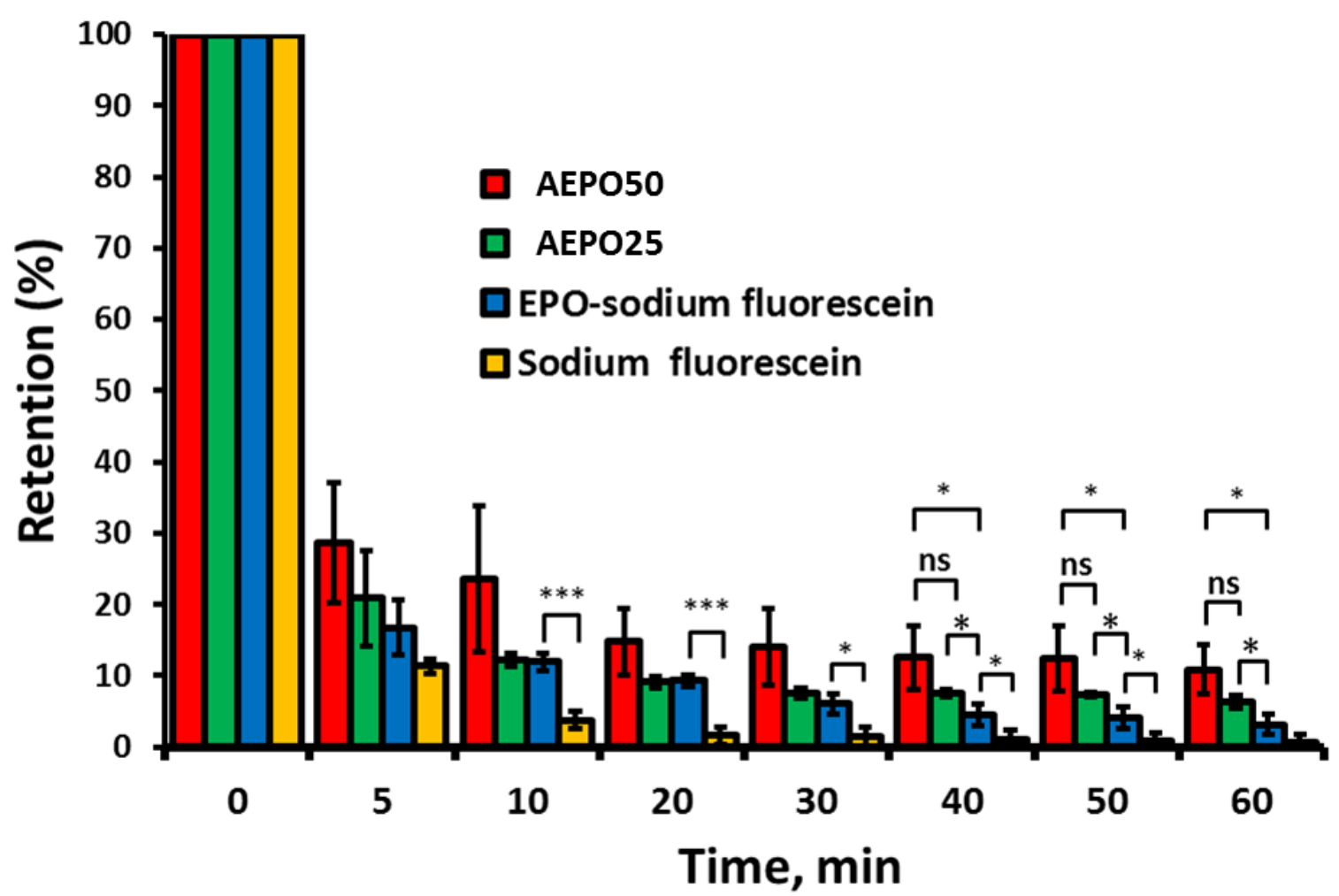

582 Figure 8. Retention of $1 \mathrm{mg} / \mathrm{mL}$ EPO, AEPO25, AEPO50 solutions with $0.001 \mathrm{mg} / \mathrm{mL}$ sodium 583 fluorescein and pure $0.001 \mathrm{mg} / \mathrm{mL}$ sodium fluorescein solution on sheep nasal mucosa as 584 washed with different volumes of $\mathrm{ANF}(\mathrm{pH}=5.7, \mathrm{n}=3$, mean $\pm \mathrm{SD}$, “*” represents $p<0.05)$. 